\title{
GcSTUA, an APSES Transcription Factor, Is Required for Generation of Appressorial Turgor Pressure and Full Pathogenicity of Glomerella cingulata
}

\author{
XingZhang Tong, ${ }^{1}$ Xiuwen Zhang, ${ }^{1}$ Kim M. Plummer, ${ }^{2}$ Kathryn M. Stowell, ${ }^{1}$ Patrick A. Sullivan, ${ }^{1}$ and \\ Peter C. Farley ${ }^{1}$ \\ ${ }^{1}$ Institute of Molecular Biosciences, Massey University, Palmerston North, New Zealand; ${ }^{2}$ Department of Botany, La Trobe \\ University, Melbourne, Australia
}

Submitted 14 February 2007. Accepted 25 April 2007.

\begin{abstract}
Glomerella cingulata, which infects a number of different hosts, gains entry to the plant tissue by means of an appressorium. Turgor pressure generated within the appressorium forces a penetration peg through the plant cuticle. A visible lesion forms as the fungus continues to grow within the host. A G. cingulata homolog (GcSTUA) of the genes encoding Asm1, Phd1, Sok2, Efg1, and StuA transcription factors in Magnaporthe grisea and other fungi was cloned and shown to be required for infection of intact apple fruit and penetration of onion epidermal cells. Mobilization of glycogen and triacylglycerol during formation of appressoria by the GcSTUA deletion mutant appeared normal and melanization of the maturing appressoria was also indistinguishable from that of the wild type. However, GcSTUA was essential for the generation of normal turgor pressure within the appressorium. As is the case for its homologs in other fungi, GcSTUA also was required for the formation of aerial hyphae, efficient conidiation, and the formation of perithecia (sexual reproductive structures).
\end{abstract}

Many phytopathogenic fungi enter their host by means of a specialized infection structure known as an appressorium (Mendgen et al. 1996). Conidia germinating on the surface of a host plant are induced to form an appressorium by a variety of physical and chemical stimuli. The appressorium adheres to the plant cuticle and forms a thick, melanized cell wall. Glycogen and triacylglycerol stored in the conidium are transferred to the appressorium and used for the synthesis of glycerol (Wang et al. 2005), which accumulates to high concentrations ( $>3 \mathrm{M}$ ) within the appressorium. The melanized cell wall is permeable to water but not glycerol. This results in the build-up of turgor pressure within the appressorium, which forces a penetration peg through the plant epidermal cell wall. Growth and branching of the penetration hypha results in the formation of a visible lesion in the

Corresponding author: P. C. Farley; E-mail: P.C.Farley@massey.ac.nz; Telephone: +64 6350 5515, ext. 7229; Fax: +6463505688.

Current addresses for X.Z. Tong: The Children's Hospital at Westmead, NSW 2145, Australia.

Sequence data for $G c S T U A$ is available from the GenBank database under accession number EF408244.

* The $e$-Xtra logo stands for "electronic extra" and indicates additional material is available online. Two supplemental figures and two supplemental tables are published online. In addition, Figures 3 and 4 appear in color online. plant tissue. This is accompanied by secretion of enzymes, such as pectin lyase (Templeton et al. 1994) and peptidases (Clark et al. 1997), which digest the plant tissue.

Appressorium differentiation and penetration of host tissue involves both cAMP signal transduction and mitogen-activated protein kinase (MAPK) pathways. Magnaporthe grisea and Colletotrichum lagenarium mutants lacking adenylate cyclase either failed to form appressoria or formed nonfunctional appressoria (Choi and Dean 1997; Yamauchi et al. 2004), whereas $M$. grisea, $C$. lagenarium, and $C$. trifolii mutants lacking the catalytic subunit of cAMP-dependent protein kinase A (PKA), encoded by $C P K A, C P K 1$, and $C t-P K A C$, respectively (Xu et al. 1997; Yamauchi et al. 2004; Yang and Dickman 1999), formed nonfunctional appressoria that failed to penetrate host tissue. This suggests that the cAMP signal transduction pathway is required for penetration and also may be required for appressorium formation. Increased lipase activity, associated with appressorium formation, and the degradation of glycogen and triacylglycerol that precedes turgor generation, are all dependent on PKA activity (Thines et al. 2000).

In M. grisea, MST11, MST7, PMK1, and MST50 encode an MAPK kinase kinase, an MAPK kinase, an MAPK, and the scaffold or adaptor protein by which these three enzymes form a functional MAPK signal transduction complex (Park et al. 2006). The MAPK encoded by $P M K 1$ is required for both mobilization of glycogen and triacylglycerols following germination of conidia (Thines et al. 2000) and subsequent appressorium formation (Xu and Hamer 1996). M. grisea mutants carrying a deletion of any one of the components of this signal transduction complex and a $C$. gloeosporioides MAPK kinase deletion mutant (Kim et al. 2000) are unable to form appressoria. These cAMP and MAPK signal transduction pathways are central to infection-related development in all the pathogenic fungi studied to date (D'Souza and Heitman 2001; Tucker and Talbot 2001) and, therefore, are assumed to have similar roles in Glomerella cingulata. In both M. grisea and C. lagenarium, a transcription factor belonging to the Ste 12 family is required for penetration peg formation (Park et al. 2004; Tsuji et al. 2003). Deletion of the gene encoding this transcription factor (MST12 or CST1, respectively) had no effect on appressorium formation or the generation of turgor pressure, suggesting that other transcription factors may be involved in these processes.

Although well characterized in a number of fungi, no member of the Asm1, Phd1, Sok2, Efg1, and StuA (APSES) family of transcription factors (Aramayo et al. 1996) has been characterized in a phytopathogenic fungus that uses an appressorium to invade its host. However, APSES transcription factors are known 
to be involved in regulating morphological changes during asexual reproduction in Fusarium oxysporum (Ohara and Tsuge 2004) and Penicillium marneffei (Borneman et al. 2002), sexual development (protoperithecia formation) in Neurospora crassa (Aramayo et al. 1996), sexual and asexual reproduction in Aspergillus nidulans (Dutton et al. 1997; Miller et al. 1991), pseudohyphal formation in Saccharomyces cerevisiae (Gimeno and Fink 1994), and hyphal and chlamydospore development in Candida albicans (Lo et al. 1997; Sonneborn et al. 1999; Stoldt et al. 1997); and to be required for expression of a subset of the phenotypic characteristics of white-phase $C$. albicans cells (Srikantha et al. 2000). As well as regulating genes involved in morphogenesis, APSES transcription factors also control the expression of genes encoding metabolic enzymes (Doedt et al. 2004; Sheppard et al. 2005), secreted enzymes (Korting et al. 2003), and cell wall proteins (Sohn et al. 2003). Furthermore, in both $S$. cerevisiae and $C$. albicans, APSES transcription factors are targets for the cAMP signal transduction pathway (Bockmuhl and Ernst 2001; Shenhar and Kassir 2001; Ward et al. 1995). Therefore, it was considered possible that a transcription factor belonging to the APSES family might be involved in appressorium formation, and this was investigated using the plant pathogen $G$. cingulata.

Fungi belonging to the genus Glomerella, or Colletotrichum, cause disease in staple horticultural crops, including the four most important food crops in Africa (American Phytopathological Society 2006; Ortiz 2003). They are also model organisms for studies of fungus-plant interactions (Perfect et al. 1999). G. cingulata, anamorph Colletotrichum gloeosporioides, whose hosts include apple (Brook 1977) and onion (Ebenebe 1980; Galvan et al. 1997; Pedrosa et al. 2004), belongs to the same taxonomic class as $M$. grisea and a number of other phytopathogens (Mitchell et al. 2003). Therefore, identification of a transcription factor involved in appressorium formation in G. cingulata can be expected to also inform our understanding of this process in other phytopathogens.

Here, we report identification of a gene encoding a $\mathrm{G}$. cingulata APSES transcription factor. We show that the deletion mutant is unable to infect intact apple fruit and establish that this is because its appressoria are unable to generate normal turgor pressure. Because mobilization of glycogen and triacylglycerol appears normal, we postulate that this transcription factor may have a role in regulating changes in metabolism on which the generation of turgor pressure depends. The transcription factor also is required for efficient conidiation and the formation of perithecia.

\section{RESULTS}

\section{Isolation and bioinformatic characterization of the G. cingulata STUA gene.}

A 7.4-kb XhoI/EcoRV fragment of $G$. cingulata genomic DNA was cloned (plasmid pXHE) and shown to contain a 2,097-bp open reading frame (ORF) interrupted by two introns (53 and $57 \mathrm{bp}$, respectively). The ORF encodes a protein 698 amino acid residues long that includes an APSES domain (residues 209 to 289) that has between 72 and 99\% identity at the amino acid level with the APSES domains of other fungal proteins. Therefore, the G. cingulata gene has been called the GcSTUA gene. At the amino acid level, the product of this gene had the highest overall identity with the proteins encoded by the $N$. crassa Asm-1 (53\%) (Aramayo et al. 1996) and $M$. grisea MSTU1 (51\%) genes (GenBank accession number $\mathrm{AB} 218802)$.

In alignments of the conceptual translation of the GcSTUA gene with the APSES proteins from N. crassa, M. grisea, $P$. marneffei, A. nidulans, and $F$. oxysporum, the methionine resi- due encoded by an ATG codon 243 bp downstream from the putative start codon for the GcSTUA gene is within six residues of the N-terminus of four of the other proteins (the protein from $F$. oxysporum is the exception and is shorter still). The context of this ATG codon (CCGCCATG) fits the consensus context sequence (YCRMMATG) for the start codons in filamentous fungal genes (Gurr et al. 1987), whereas the context of the upstream ATG codon (GGTACATG) does not. However, both ATG codons are within the sequences recovered in 5' rapid amplification of cDNA ends (RACE) experiments (data not shown), and translation of most fungal genes begins at the first ATG (Gurr et al. 1987).

The location of the introns in the GcSTUA ORF was confirmed by sequencing a polymerase chain reaction (PCR) product obtained by $3^{\prime}$ RACE (data not shown). These introns interrupt the sequence encoding the APSES domain and their location is conserved in the ORFs encoding all the known fungal APSES proteins except the intronless $N$. crassa Asm- 1 ORF. The length of the GcSTUA transcript was estimated from northern blots to be approximately $3.7 \mathrm{~kb}$. Analysis the G. cingulata genomic DNA sequence revealed a putative third intron located $865 \mathrm{bp}$ upstream of the start of the ORF and three putative upstream ORFs (uORFs) in this region. An intron located $987 \mathrm{bp}$ upstream of the ORF is excised from the longer of the two A. nidulans StuA transcripts (Miller et al. 1992) and putative introns also are present upstream of the A. fumigatus and the $M$. grisea ORFs (748 and $934 \mathrm{bp}$, respectively). One of the $G$. cingulata uORFs is, like the A. nidulans uORF that regulates translation of the transcript in which it is present (Wu and Miller 1997), located within this intron; furthermore, as in $A$. nidulans, its stop codon is also the $3^{\prime}$ splice site of the intron. Southern blot analysis indicated that a single copy of GcSTUA was present in the genome of this fungus (data not shown).

Analysis of the sequences flanking the GcSTUA gene revealed a partial ORF downstream of GcSTUA. Over the region for which amino acid sequence could be deduced, the protein encoded by this ORF had a high level of identity with hypothetical proteins from Gibberella zeae (59\% identical to FG10148.1), M. grisea (50\% identical to MG01817.4), Chaetomium globosum (46\% identical to CHGG_07023), and N. crassa $(45 \%$ identical to NCU04325.1). In the genomes of $M$. grisea, A. nidulans, and $N$. crassa, a similarly placed ORF is present, but the hypothetical proteins encoded by these genes (MG00693.4, AN5837.3, and NCU01413.1) have less than 15\% identity with the Glomerella cingulata hypothetical protein.

\section{Construction and molecular characterization of GcSTUA mutants.}

In order to determine whether GcSTUA is required for appressorium formation, deletion mutants were constructed in which three quarters of the GcSTUA gene, including the most $5^{\prime}$ of the two possible start codons and the APSES domain, was replaced by a hygromycin resistance cassette. G. cingulata was transformed with the deletion vector pSXH and 20 randomly selected transformants were screened, using PCR and Southern blot analysis (data not shown). With genomic DNA from the wild type, the probe hybridized to a single 7.4-kb EcoRV fragment. Replacement of the GcSTUA gene by the hygromycin resistance cassette would introduce an EcoRV site and, therefore, two EcoRV fragments (2.6 and $6.6 \mathrm{~kb}$ ) would hybridize with the probe. Because the flanking recognition sites for EcoRV lay outside the sequences used to target the deletion vector to the GcSTUA locus, hybridization of the probe to these two fragments would establish that the desired replacement event had occurred without loss of flanking sequences. In all, 19 of the 20 transformants showed this pattern of hybridization, and two transformants, D42 and D43, were 
selected for further study. An additional ectopic integration event had occurred in the remaining transformant (data not shown). The two screens gave consistent results. The deletion mutants were easily distinguishable from the wild type because they did not form aerial hyphae, their colonies remained white, and their mycelium was wettable. Expression of the remaining fragment of the GcSTUA gene in the deletion mutant D43 was close to the limits of detection by reverse-transcription (RT)PCR (data not shown).

Construction of a GcSTUA complementation mutant was attempted using a vector designed for random integration of the GcSTUA gene into the genome of the deletion mutant by a single crossover event. Transformants that showed the wild-type colony morphology were obtained. In all of them, the integration event had placed the reintroduced full-length GcSTUA gene under the control of the endogenous GcSTUA promoter without loss of either the hygromycin resistance cassette or the associated fragment of the GcSTUA gene. However, these transformants were unstable. Reversion to the deletion mutant phenotype was accompanied by loss of the reintroduced GcSTUA gene (data not shown).

Stable reintroduction of the GcSTUA gene was achieved using a vector ( $\mathrm{pXHE-phleo-R)} \mathrm{designed} \mathrm{to} \mathrm{replace} \mathrm{the} \mathrm{hygromycin}$ resistance cassette with a copy of the GcSTUA gene in tandem with a downstream phleomycin resistance marker. Of 25 randomly chosen phleomycin-resistant colonies, 12 displayed a wild-type phenotype and 2 of these (R5 and R13) were chosen for Southern blot analysis. The hybridization patterns obtained using HindIII-digested DNA and XhoI-digested DNA (data not shown) were consistent with restoration of the GcSTUA gene and its promoter, and replacement of the hygromycin B phosphotransferase gene by the gene encoding a phleomycin binding protein.

\section{Mycelial growth, conidiation, and formation of perithecia.}

The GcSTUA gene was not required for vegetative hyphal growth on potato dextrose agar plates. After 36 to $48 \mathrm{~h}$ of growth on potato dextrose agar plates inoculated with a single conidium, differences in hyphal branching were observed between the wild type and the deletion mutants. In the deletion mutants, hyphae were less branched and the colony more com- pact compared with the wild type or the restoration mutants, which had formed an open network of branched hyphae (Fig. $1)$. However, radial growth rates of the wild type $(0.47 \pm 0.09$ $\left.\mathrm{mm} \mathrm{h}^{-1}\right)$ or either restoration mutant $\left(\mathrm{R} 5,0.59 \pm 0.20 \mathrm{~mm} \mathrm{~h}^{-1}\right.$; $\mathrm{R} 13,0.56 \pm 0.19 \mathrm{~mm} \mathrm{~h}^{-1}$ ) were not statistically significantly different (Student's $t$ test, $P>0.1, n=6$ ) from those of either deletion mutant (D42, $0.48 \pm 0.11 \mathrm{~mm} \mathrm{~h}^{-1}$; D43, $0.45 \pm 0.12$ $\mathrm{mm} \mathrm{h}^{-1}$ ). In contrast, whereas colonies of the wild type and both restoration mutants produced fluffy aerial hyphae, both deletion mutants produced only stunted aerial hyphae (Fig. 2) which collapsed from the center of the colony outward as it aged. When a drop of water was applied to the mycelium of either deletion mutant, the water dispersed immediately, whereas water drops sat on the surface of wild-type or restoration mutant colonies for hours without dispersing.

The GcSTUA gene was required for efficient conidiation. Orange-colored clumps of conidia were never observed in colonies of the deletion mutants. Microscopically, conidiophores and their associated conidia were present in colonies of the wild type and restoration mutants grown on potato dextrose agar plates under a 12-h light-and-dark cycle; whereas, in colonies of the deletion mutants, conidiophores were observed to have just a single conidium associated with them. Both deletion mutants produced statistically significantly fewer conidia than the wild type or either restoration mutant under all the conditions tested (Table 1).

The GcSTUA gene also was required for the formation of perithecia. After 7 to 10 days of growth on potato dextrose agar plates, colonies of either the wild type or the restoration mutants started to turn gray to black in color. Young perithecia were present in these colonies and, as they matured, the colonies became a dark black color and eight ascospores could be seen within the asci. In contrast, colonies of both deletion mutants never became gray or black and no perithecia were observed in these colonies.

\section{Adhesion and germination of conidia, formation of appressoria, and lipid and glycogen mobilization during appressorium formation.}

No differences in the adhesion of conidia, their germination, or the formation of appressoria on a hydrophobic surface were
WT
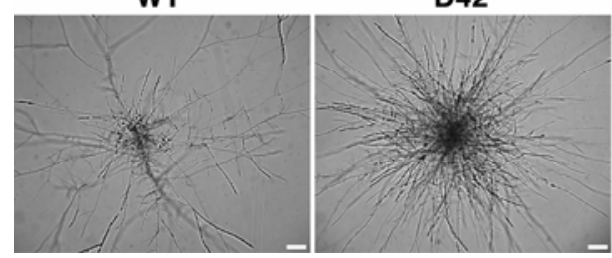

D43

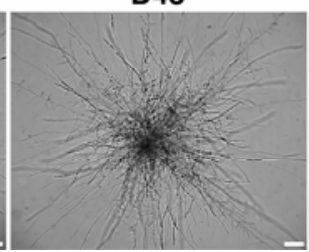

R5

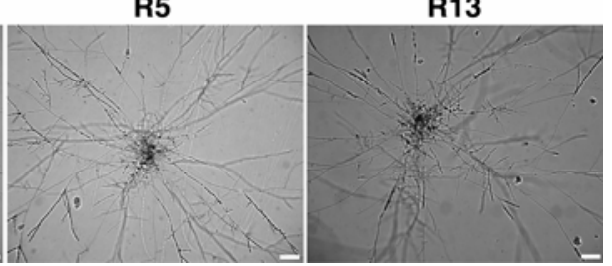

Fig. 1. Morphology of colonies formed by single conidia of the wild type (WT) and deletion (D42 and D43) and restoration (R5 and R13) mutants on potato dextrose agar plates after $48 \mathrm{~h}$ of incubation at $22^{\circ} \mathrm{C}$. Bar $=0.1 \mathrm{~mm}$.
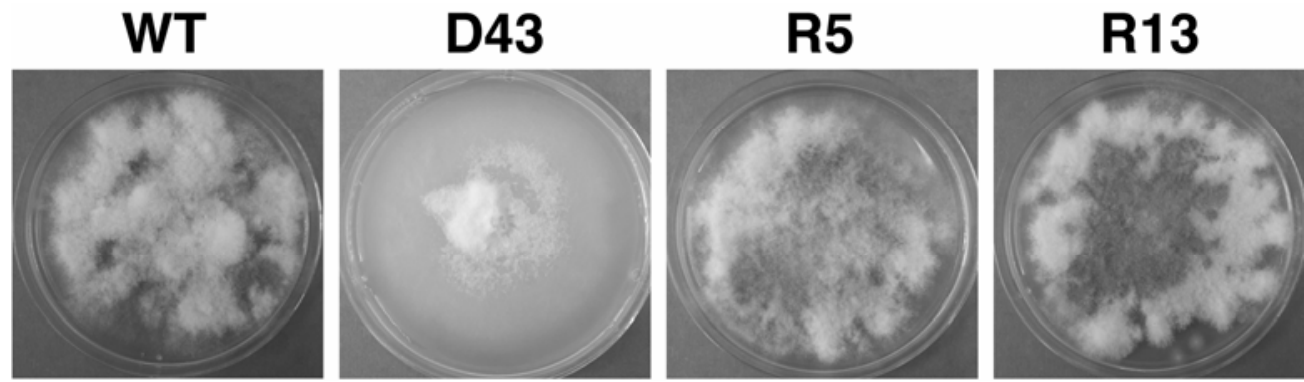

Fig. 2. Morphology of colonies of the wild type (WT) and deletion mutant (D43) and restoration mutants (R5 and R13) after 7 days of growth in the dark at $25^{\circ} \mathrm{C}$ on potato dextrose agar plates. 
observed between either deletion mutant and those of the wild type or the restoration mutants (data not shown). Similar results were obtained for germination of conidia and appressorium formation on apple wax-coated glass slides (data not shown) and on onion epidermal peels (Table 2). Furthermore, there were no differences in the size, shape, and melanization of the appressoria formed by the mutants and the wild type. Glycogen and lipid droplets were present in the ungerminated conidia of the wild type and all four mutants, and no differences in the time course of mobilization of these energy reserves were observed (Fig. 3).

\section{Pathogenicity.}

Pathogenicity tests were performed on Granny Smith apple because the strain of $G$. cingulata used in this study was originally isolated from this apple cultivar. Inoculation of surfacesterilized apple fruit with conidia of the wild type resulted in the appearance of surface lesions approximately 7 days postinoculation. As the lesion developed, concentric rings of acervuli ruptured the apple cuticle and exposed a gelatinous mass of pink conidia. After 15 to 30 days of incubation, black perithecia had developed on the surface of the lesion (Fig. 4). In contrast, the GcSTUA deletion mutants were unable to infect intact Granny Smith fruit (Table 3). The null hypothesis, that the association between inoculum and infection was random, was tested using Fisher's exact test on a two-by-six contingency table. The probability of obtaining the data shown in Table 3 for the number of unwounded apple fruit infected is less than 0.001 and, therefore, the null hypothesis was rejected. Even after a further 13 days of incubation, no lesions appeared on unwounded apple fruit inoculated with conidia of either deletion mutant. The GcSTUA restoration mutants were indistinguishable from the wild type and each other with respect to both number of lesions per fruit and diameter of lesions (Student's $t$ test, $P>0.1$ ).

To test whether the deletion mutants were able to colonize apple fruit if appressorial penetration of the epidermis was not necessary, conidia were applied to fresh puncture wounds and the lesions that developed were examined. On these wounded fruit, there was no statistically significant difference (Student's $t$ test, $P>0.1)$ in the diameter of lesions produced by the wild type and any of the mutants (Table 3 ). None of the negative control apple fruit (sterile water as inoculum) became infected, but all the wounded fruit inoculated with either mutant or wild type $G$. cingulata conidia became infected. Unlike the wild

Table 1. Yield of conidia obtained from the wild type and the GcSTUA deletion (D) and restoration (R) mutants on potato dextrose agar plates, potato dextrose broth (PDB), and liquid induction medium (IM) ${ }^{\mathrm{a}}$

\begin{tabular}{lcrr}
\hline & & \multicolumn{2}{c}{$\mathbf{1 0}^{\mathbf{5}} \times \mathbf{\text { no. of conidia/ml }}$} \\
\cline { 3 - 4 } Source & $\mathbf{1 0}^{\mathbf{- 5}} \times \mathbf{\text { no. of conidia/plate }}$ & PDB & \multicolumn{1}{c}{$\mathbf{I M}$} \\
\hline Wild type & $2,200 \pm 1450(20)$ & $97 \pm 20(5)$ & $558 \pm 137(5)$ \\
D42 & $1.4 \pm 0.9(20)^{*}$ & $3.7 \pm 0.7(5)^{*}$ & $87 \pm 17(5)^{*}$ \\
D43 & $1.1 \pm 0.7(20)^{*}$ & $3.0 \pm 0.7(5)^{*}$ & $75 \pm 14(5)^{*}$ \\
R5 & $2,300 \pm 1850(20)$ & $109 \pm 21(5)$ & $570 \pm 153(5)$ \\
R13 & $1,950 \pm 1300(20)$ & $98 \pm 20(5)$ & $604 \pm 164(5)$ \\
\hline
\end{tabular}

${ }^{a}$ Values shown are the mean \pm standard deviation for the number of plates or cultures shown in parenthesis. Plates overlaid with a cellophane membrane were inoculated with mycelial plugs and incubated at $22^{\circ} \mathrm{C}$ under a $12-\mathrm{h}$ light-and-dark cycle. PDB cultures were inoculated with $10^{5}$ conidia ml $\mathrm{m}^{-1}$ and incubated with shaking at $25^{\circ} \mathrm{C}$ for 7 days. IM medium (Roncal and Ugalde 2003) was inoculated with blended mycelium and incubated with shaking at $25^{\circ} \mathrm{C}$ for 3 days. An asterisk (*) indicates statistically significantly less than either the wild type or the restoration mutants (Student's $t$ test, $P<0.001$ ). There was no statistically significant difference between conidia production by the wild type and either restoration mutant on any of these media (Student's $t$ test, $P>0.3$ ). type and the restoration mutants, neither deletion mutant produced acervuli or perithecia, and the lesion produced by the deletion mutants was light brown in color rather than dark black, as was the case for the wild type and the restoration mutants (Fig. 4). Furthermore, the lesion produced by the deletion mutants was significantly softer (Student's $t$ test, $P<0.01, n=$ 8 ) than that produced by either the wild type or the restoration mutants (Table 3).

\section{Penetration of epidermal cells and generation of turgor pressure by appressoria.}

The GcSTUA deletion mutants were able to infect wounded but not unwounded apple fruit; therefore, the ability of their appressoria to form a penetration peg on onion epidermal peels was investigated. Use of onion epidermal peel permits observation of fungal structures that penetrate the epidermal cells (Xu et al. 1997). Wild-type conidia formed appressoria on the surface of onion epidermal peels within $24 \mathrm{~h}$ (94\% of the conidia had germinated and $99 \%$ of the germinated conidia had formed appressoria) and, by $72 \mathrm{~h}$ postinoculation, an extensive hyphal network was present beneath the epidermal cells. At 48 $\mathrm{h}$ postinoculation, it was possible to trace individual hyphae from beneath the epidermal cells back through the epidermal cell layer to the appressorium from which it originated (Fig. 5). A similar result was obtained with the restoration mutants; however, although the GcSTUA deletion mutants germinated (94 to $95 \%$ of the conidia) and formed appressoria (95\% of the germinated conidia), penetration of the onion epidermal cells was never observed (Table 2).

Successful penetration of host tissue requires the development of hydrostatic pressure within the appressorium (Howard et al. 1991; Wang et al. 2005). Appressorial turgor pressure for the GcSTUA deletion mutants, assessed using the incipient cytorrhysis assay (Howard et al. 1991), was significantly lower than that of the wild type and restoration mutants. Whereas not more than $10 \%$ of the appressoria formed by the wild type or the restoration mutants collapsed in $2 \mathrm{M}$ glycerol, between 49 and $65 \%$ of the appressoria formed by either deletion mutant collapsed under these conditions (Table 4). At higher concentrations of glycerol, the proportion of appressoria that collapsed increased (data not shown) but was always statistically signifi-

Table 2. Appressorium formation and penetration of onion epidermal cells for the wild type and the GcSTUA deletion (D) and restoration (R) mutants ${ }^{\mathrm{a}}$

\begin{tabular}{lccc}
\hline Source & $\begin{array}{c}\text { Germination } \\
(\boldsymbol{\%})^{\mathbf{b}}\end{array}$ & $\begin{array}{c}\text { Appressorium } \\
\text { formation }(\boldsymbol{\%})^{\mathbf{b}}\end{array}$ & $\begin{array}{c}\text { Penetration } \\
(\boldsymbol{\%})^{\mathbf{c}}\end{array}$ \\
\hline Wild type & $98.6 \pm 1.3$ & $93.8 \pm 1.5$ & $7.3 \pm 0.6$ \\
D42 & $95.1 \pm 2.3$ & $95.4 \pm 2.1$ & $0 \pm 0^{*}$ \\
D43 & $94.9 \pm 3.8$ & $94.3 \pm 0.6$ & $0 \pm 0^{*}$ \\
R5 & $98.9 \pm 1.3$ & $94.8 \pm 1.4$ & $7.7 \pm 0.6$ \\
R13 & $98.9 \pm 1.3$ & $94.2 \pm 2.3$ & $6.7 \pm 1.5$ \\
\hline
\end{tabular}

${ }^{a}$ Values shown are the mean \pm standard deviation for three randomly selected regions of the onion epidermal peel, each containing at least 100 conidia. Appressoria were induced on onion epidermal peels.

${ }^{b}$ Percentage of germinated conidia and percentage of germinated conidia that had formed an appressorium were determined after $24 \mathrm{~h}$ of incubation at $22^{\circ} \mathrm{C}$. There was no statistically significant difference (Student's $t$ test, $P>0.1, n=3$ ) between the wild type and any of the mutants for either of these parameters.

${ }^{\mathrm{c}}$ After a further $24 \mathrm{~h}$ of incubation at $22^{\circ} \mathrm{C}$, the number of appressoria which had penetrated the epidermal cells was assessed. For the wild type and restoration mutants, the percent penetration figure is probably an underestimate because hyphae that could not be tracked back to an appressorium were ignored. No penetration of the epidermal cells by appressoria of the deletion mutants was ever observed. An asterisk (*) indicates that penetration by the deletion mutants was statistically significantly different from either the wild type or the restoration mutants (Student's $t$ test, $P<0.01$, $n=3$ ), but there was no statistically significant difference (Student's $t$ test, $P>0.1, n=3$ ) between the wild type and the restoration mutants. 
cantly greater for the deletion mutants compared with either the wild type or the restoration mutants (Student's $t$ test, $P<$ $0.01, n=3)$.

\section{DISCUSSION}

Appressorium-forming fungi breach the physical barrier to invasive growth within their host when the rising turgor pressure within the appressorium forces the penetration peg through the plant cuticle and into the underlying epidermal cell. In both $M$. grisea and Colletotrichum lagenarium, penetration peg formation has been shown to be under the control of a transcription factor (encoded by MST12 and CST1, respectively) belonging to the Ste12 family. Appressorial turgor pressure was not measured in CST1 deletion mutants (Tsuji et al. 2003) but was shown to be normal in MST12 deletion mutants (Park et al. 2004). This suggested that the two processes, turgor pressure generation and penetration peg formation, are separately controlled. In this study, the generation of turgor pressure in $G$. cingulata appressoria has been shown to be controlled by a transcription factor (encoded by GcSTUA) that belongs to the APSES family.

Southern blot analysis suggested that just a single copy of GcSTUA is present in the G. cingulata genome. This is consistent with the results of a BLASTN analysis of four filamentous fungal genomes (A. nidulans, A. fumigatus, M. grisea, and $N$. crassa) in which no other sequence with significant similarity (E value $<0.06$ ) to their own STUA gene was found (unpublished data). The A. nidulans STUA mRNAs contain long 5' untranslated regions and uORFs, and transcription begins either upstream of or within the intron located upstream of the coding sequence (Miller et al. 1992). The length of the GcSTUA mRNA, which is similar to that of the A. nidulans STUA mRNA, and the presence and location of the G. cingulata upstream intron and uORFs suggest that expression of GcSTUA is, like the A. nidulans STUA gene, controlled at the level of both transcription and translation. The intron and uORFs also are found in M. grisea (unpublished data).

In the deletion mutants, most, but not all, of the GcSTUA gene was replaced by the hygromycin resistance cassette. Because a transcript containing the remaining GcSTUA gene fragment was present in the deletion mutant, it is possible that the deletion mutant phenotype arises from a dominant negative effect of the protein encoded by this fragment of the GcSTUA gene. However, this is unlikely because complementation of the deletion mutant was achieved by reintroduction of the fulllength GcSTUA gene in the continuing presence of the GcSTUA gene fragment. The morphology of these complementation mutants was restored to that of the wild type. Aerial hyphae were produced, colonies were unwettable, and conidia

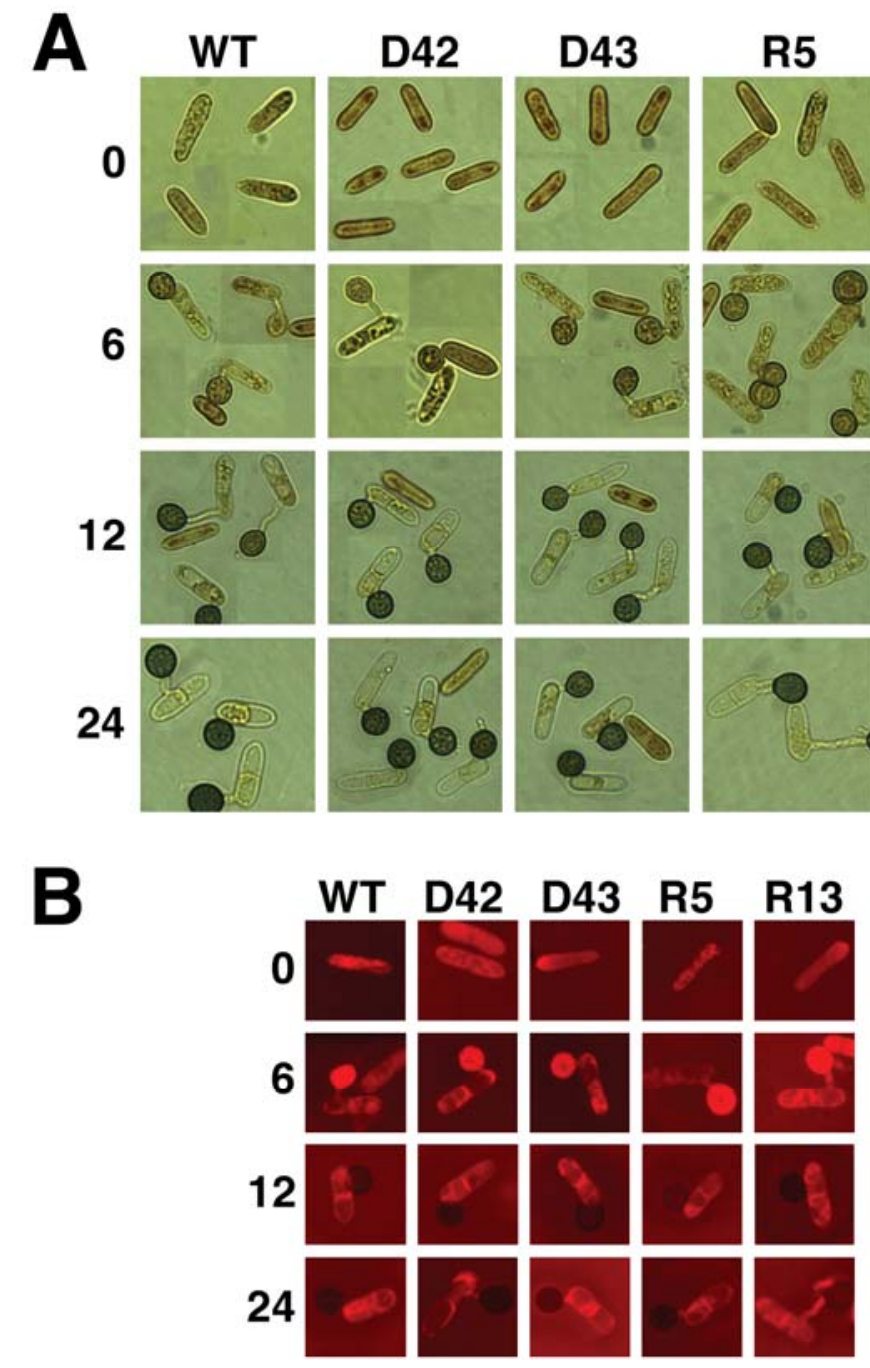

Fig. 3. Mobilization of glycogen and lipid reserves in the germinating conidia and differentiating appressoria of the wild type (WT) and deletion (D42 and D43) and restoration (R5 and R13) mutants. Cells were stained and examined microscopically 0, 6, 12, and $24 \mathrm{~h}$ after inoculation of conidia onto a hydrophobic surface. A, Iodine-stained cells and B, Nile Red-stained cells. 
production was comparable with that of the wild type. Further characterization of these complementation mutants was not attempted because these mutants were not stable.

The failure of ectopic integration events to complement the deletion mutant may arise if random integration involved the GcSTUA gene itself or if an incomplete promoter prevented correct expression of a randomly integrated copy of the gene. The effect of promoter length in complementation experiments has been noted for both the $A$. nidulans and $P$. marneffei homologs of GcSTUA. In A. nidulans, 4,095 bp of sequence upstream of the start codon was required for full complementation of the deletion mutant phenotype (Wu and Miller 1997) and, in $P$. marneffei, which lacks the upstream intron, 3,598 bp was required (Borneman et al. 2002). To confirm that the phenotype of the deletion mutant was due to deletion of GcSTUA and not an undetected secondary mutation, the GcSTUA gene was reintroduced into its native locus. This approach also has been used with the A. fumigatus STUA deletion mutant (Sheppard et al. 2005). The phenotype of the G. cingulata restoration mutants was indistinguishable from that of the wild type.

The absence of aerial hyphae in the GcSTUA deletion mutant was consistent with the appearance of $F$. oxysporum, $N$. crassa, and A. nidulans deletion mutants (Aramayo et al. 1996; Clutterbuck 1969; Ohara and Tsuge 2004). Indeed, the $A$. nidulans mutants were originally named stu (for stunted) because of this (Clutterbuck 1969). The wettability of the GcSTUA deletion mutants and the known role of hydrophobins or repellents in the formation of aerial hyphae (Kershaw and

\section{WT}
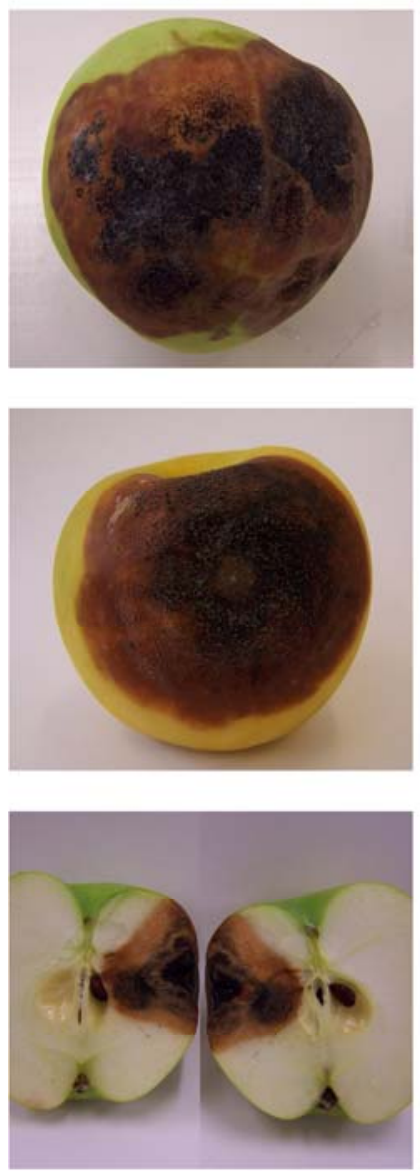

D43
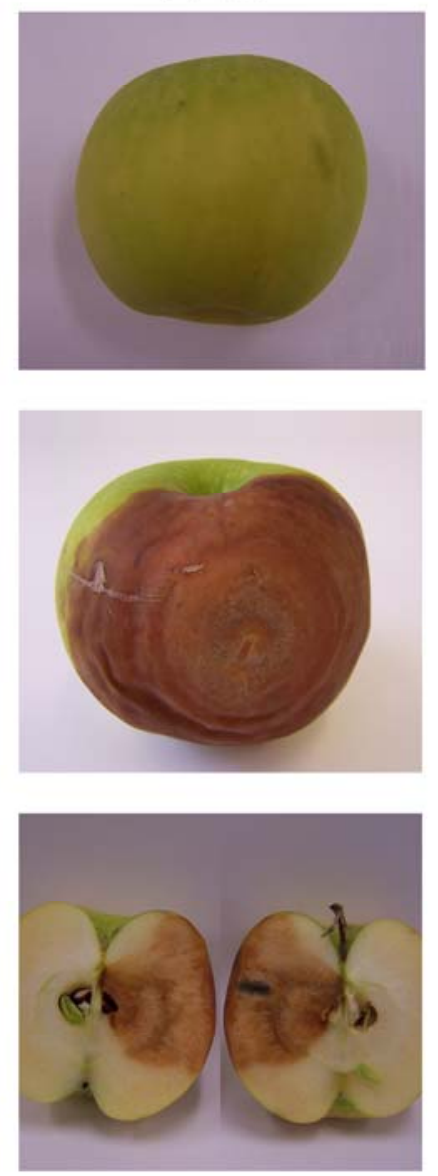

R5
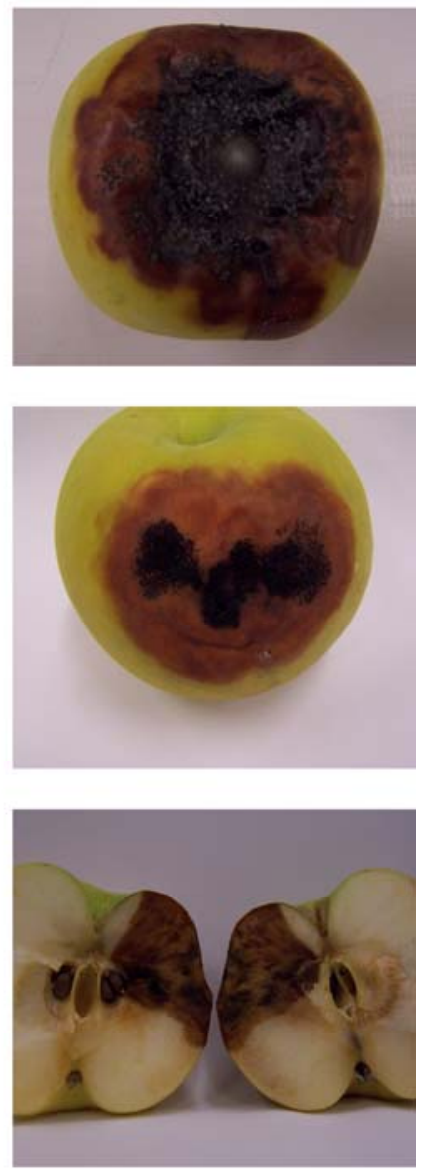

Fig. 4. Lesions formed on unwounded (top row) and wounded (middle and bottom rows) apple fruit by the wild type (WT), deletion mutant (D43), and restoration mutant (R5) 28 days after inoculation. The surface lesions are shown in the top and middle rows and a cross-section through the lesion formed on wounded fruit in the bottom row.

Table 3. Pathogenicity of the wild type and the GcSTUA deletion (D) and restoration (R) mutants on Granny Smith apple fruit ${ }^{\mathrm{a}}$

\begin{tabular}{lcccccc}
\hline & & \multicolumn{2}{c}{ Lesions on unwounded fruit } & & \multicolumn{2}{c}{ Lesions on wounded fruit } \\
\cline { 3 - 3 } Source & No. of unwounded fruit infected & No. per fruit & Diameter $(\mathbf{c m})$ & & Diameter (cm) & Firmness (kg) \\
\hline Wild type & $37(40)$ & $2.25 \pm 1.50(40)$ & $2.0 \pm 1.3(90)$ & & $2.9 \pm 0.3(8)$ & $11.08 \pm 2.55(8)$ \\
D42 & $0(16)$ & $0 \pm 0 *(16)$ & $0 \pm 0(0)$ & & $3.2 \pm 0.4(8)$ & $4.90 \pm 1.47 *(8)$ \\
D43 & $0(24)$ & $0 \pm 0 *(24)$ & $0 \pm 0(0)$ & & $2.9 \pm 0.3(8)$ & $5.49 \pm 1.27 *(8)$ \\
R5 & $23(24)$ & $1.83 \pm 1.24(24)$ & $1.7 \pm 1.1(44)$ & & $3.0 \pm 0.4(8)$ & $10.30 \pm 2.06(8)$ \\
R13 & $15(16)$ & $2.06 \pm 1.18(16)$ & $1.7 \pm 1.4(33)$ & & $3.2 \pm 0.5(8)$ & $10.69 \pm 2.65(8)$ \\
Control & $0(40)$ & $0 \pm 0^{*}(40)$ & $0 \pm 0(0)$ & & $0 \pm 0 * *(8)$ & $82.38 \pm 17.85^{* *}(8)$ \\
\hline
\end{tabular}

${ }^{a}$ Except in column 2, values shown are the mean \pm standard deviation. Values shown in parentheses are the total number of apple fruit inoculated, except in column 4, where they are the number of lesions measured. Parameters were measured 12 and 14 days postinoculation for unwounded and wounded fruit, respectively. Control apple fruit were inoculated with sterile water; ${ }^{*}=$ statistically significantly different from the wild type or either restoration mutant (Student's $t$ test, $P<0.01$ ) and $* *=$ statistically significantly different from the wild type or any of the mutants (Student's $t$ test, $P<0.01$ ). 
Talbot 1998; Teertstra et al. 2006) suggests that expression of these or other proteins with similar properties is controlled by GcSTUA. The Candida albicans APSES transcription factor Efg1p regulates expression of genes encoding putative cell wall proteins (Doedt et al. 2004). Efg1p also regulates proteinase secretion (Korting et al. 2003), suggesting that the softer lesions produced by the GcSTUA deletion mutants on wounded apple fruit may be due to altered secretion of hydrolytic enzymes. A role for GcSTUA in both sexual and asexual reproduction also was not unexpected, given the role of homologous APSES transcription factors in these processes in other filamentous fungi (Aramayo et al. 1996; Miller et al. 1991; Ohara and Tsuge 2004).

Although FoSTUA is not required for pathogenicity (invasion, colonization, or development of symptoms) by the plant pathogen F. oxysporum (Ohara and Tsuge 2004), GcSTUA is required for pathogenicity in G. cingulata. Unlike $F$. oxysporum, which

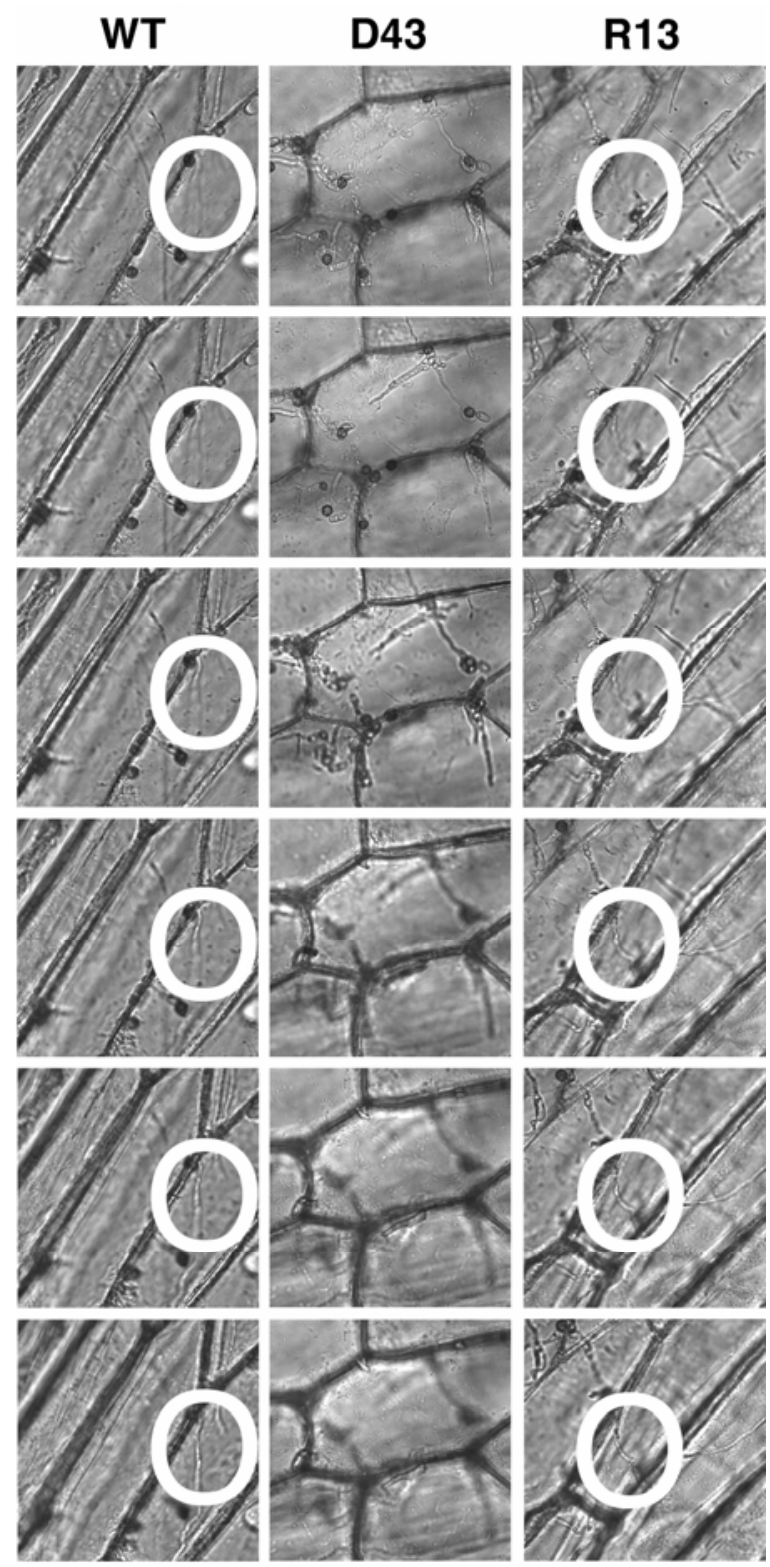

Fig. 5. Images at sequential focal planes through onion epidermal peels (adaxial surface of the epidermal peel in the top row of the figure) inoculated, on their adaxial surface, with conidia of the wild type (WT), deletion mutant (D43), and restoration mutant (R13). An appressorium of the wild type and the restoration mutant that penetrated the epidermal cells is circled. invades its host by means of direct hyphal penetration of host cells (Olivain and Alabouvette 1999), G. cingulata invades its host by means of an appressorium. Turgor pressure in the appressoria of GcSTUA deletion mutants was lower than in the wild type; however, no differences in melanization, or mobilization of either glycogen or triacylglycerol, were detected. Reduced turgor pressure might arise from changes in metabolism or leakage of glycerol from the appressorium. The apparently normal melanization of appressoria formed by the deletion mutant suggests that metabolism of the products of glycogen or triacylglycerol degradation is altered in these mutants. This possibility is further supported by the observation that another member of the APSES family has been shown to regulate the expression of genes involved in central metabolic pathways (Doedt et al. 2004).

Further experiments will be required to establish the network of interactions that control the expression of GcSTUA and the activity of the APSES transcription factor it encodes. It will be of particular interest to establish whether the cAMP or MAPK signaling pathway is involved and how the activity of the two transcription factors required for breaching the plant cuticle is coordinated.

\section{MATERIALS AND METHODS}

Fungal strains and culture conditions.

G. cingulata strain ICMP11016 and the mutants derived from it were cultured as described previously (Plummer et al. 2004). Radial growth rates were calculated from duplicate measurements of colony diameter for plates inoculated with 5-mm agar plugs of mycelium.

\section{Cloning the GcSTUA gene.}

Degenerate PCR was performed with primer no. 3 and primer no. 7 (Table 5) to generate a 432-bp fragment of G. cingulata genomic DNA. The sequences of these primers were based on the amino acid sequences ATLWEDE and YHPTNQS that are conserved among the fungal APSES transcription factor family. The PCR reaction $(20 \mu \mathrm{l})$ contained $G$. cingulata wild-type genomic DNA $(0.1 \mu \mathrm{g})$, Taq DNA polymerase buffer, $200 \mu \mathrm{M}$ each dNTP, $2.5 \mu \mathrm{M}$ each primer, and 0.4 units of Taq DNA polymerase (Roche, Mannheim, Germany). The thermocycler

Table 4. Incipient cytorrhysis assay for appressoria of the wild type and the GcSTUA deletion (D) and restoration (R) mutants ${ }^{\mathrm{a}}$

\begin{tabular}{lcc}
\hline & \multicolumn{2}{c}{ Collapsed appressoria $(\boldsymbol{\%})^{\mathbf{b}}$} \\
\cline { 2 - 3 } Source & $\mathbf{1 2} \mathbf{~ h}$ & $\mathbf{2 4} \mathbf{~ h}$ \\
\hline Wild type & $7.4 \pm 2.2$ & $6.6 \pm 2.2$ \\
D42 & $63.2 \pm 4.9^{*}$ & $48.9 \pm 4.1^{*}$ \\
D43 & $65.3 \pm 4.2^{*}$ & $58.9 \pm 7.0^{*}$ \\
R5 & $6.3 \pm 1.8$ & $7.2 \pm 3.4$ \\
R13 & $6.2 \pm 1.3$ & $10.4 \pm 3.4$ \\
\hline
\end{tabular}

a Values shown are the mean \pm standard deviation for three independent experiments. Appressoria were induced on a hydrophobic surface and, after either 12 or $24 \mathrm{~h}$ of incubation at $22^{\circ} \mathrm{C}$, the water surrounding the appressoria was removed and replaced by $2 \mathrm{M}$ glycerol. In each experiment, the number of appressoria and the number of collapsed appressoria were determined in each of three randomly selected regions of the surface. At least 100 appressoria were counted in each experiment.

b An asterisk (*) indicates that the percentage of collapsed appressoria for either deletion mutant was statistically significantly different compared with the wild type or either restoration mutant (Student's $t$ test, $P<0.01$, $n=3$ ). There was no statistically significant difference in the percentage of collapsed appressoria between the wild type and either restoration mutant at either timepoint (Student's $t$-test, $\mathrm{P}>0.01, n=3$ ), nor was there any statistically significant difference between the percentage of collapsed appressoria at the different timepoints for either the wild type or any of the mutants (Student's $t$ test, $P>0.01, n=3$ ). 
conditions were $2 \mathrm{~min}$ at $94^{\circ} \mathrm{C}$; followed by 34 cycles of $10 \mathrm{~s}$ at $94^{\circ} \mathrm{C}, 30 \mathrm{~s}$ at $60^{\circ} \mathrm{C}$, and $30 \mathrm{~s}$ at $72^{\circ} \mathrm{C}$; and a final incubation for $5 \mathrm{~min}$ at $72^{\circ} \mathrm{C}$. All the sequences from BLASTX analysis of the sequence of this PCR product with $\mathrm{E}$ values less than 1e-15 were from fungal transcription factors that contain an APSES domain.

Additional overlapping sequence data then was obtained using the single-specific-primer PCR strategy (Shyamala and Ames 1989). Genomic DNA was digested with SacI, purified by phenol/chloroform extraction, and ligated to SacI-digested pBlueScriptII. The ligation mixture then was used as template in PCR reactions containing a gene-specific primer (primer no. 4) and a vector-specific primer (T7 or T3).

A G. cingulata subgenomic library was prepared in pBlueScriptII using DNA in the size range 3.8 to $4.3 \mathrm{~kb}$ prepared by agarose gel electrophoresis following digestion of genomic DNA with XhoI. A 596-bp probe, amplified from genomic DNA with primer no. 2 and primer no. 5 , was used to screen the library, and a plasmid (pXho41) containing a 4,114bp insert was isolated. The size of the insert was consistent with the size of the hybridizing XhoI fragment seen in Southern analysis (data not shown), and the insert contained the 5' end of an ORF that included the sequence of GcSTUA already known from the two PCR experiments.

Plasmid rescue was performed with genomic DNA from a G. cingulata disruption mutant (Bowen et al. 1995) in which a pAN7-1 (Punt et al. 1987) -based vector had integrated into the GcSTUA gene. The DNA was digested with EcoRV (for which there was no recognition site within the disruption vector), purified by phenol/chloroform extraction, self-ligated in an overnight incubation at $4^{\circ} \mathrm{C}$, and used to transform $E s$ cherichia coli DH5 $\alpha$ cells. Southern blot analysis was used to identify a plasmid (pERV3) that arose from self-ligation of a genomic EcoRV fragment containing the disruption vector. A 4-kb HindIII/EcoRV fragment that contained the 3' end of GcSTUA and $2.5 \mathrm{~kb}$ of downstream sequence was subcloned from pERV3 into pBluescriptII (to give plasmid pHE40) and the insert sequenced. The partial ORFs in plasmids pXho41 and pHE40 overlapped by 722 bp. Using the unique NotI recognition site within this overlapping region and the NotI recognition site in the multiple cloning site of the vectors, NotI fragments from $\mathrm{pXho} 41$ and $\mathrm{pHE} 40$ were combined to generate a full-length clone of the GcSTUA genomic locus (a 7.4-kb $X h o I / E c o R V$ insert in plasmid pXHE). The restriction map of the insert in pXHE was consistent with the results of Southern blot analysis of $G$. cingulata DNA. PCR analysis, with pXHE or genomic DNA as template, further confirmed that the insert in $\mathrm{pXHE}$ represented the wild-type locus.

Table 5. Primer sequences

\begin{tabular}{ll}
\hline Primer & \multicolumn{1}{c}{ Sequence $\left(\mathbf{5}^{\prime} \mathbf{- 3} \mathbf{3}^{\prime}\right)$} \\
\hline No. 1 & GTCGGTGCATACGATAGCTAC \\
No. 2 & AGATCTATGAATCAACCCGCTGCCGAC \\
No. 3 & GCCAC(G/A/T)T(C/T)(A/G)TGGGA(A/G)GA(C/T)GAG \\
No. 4 & GCTTGGTGCCATTGATCATGTG \\
No. 5 & AGATCTCTCAACTTACCAGACACCCTTC \\
No. 6 & GCGAAGTCGAGTGCCCTCTC \\
No. 7 & T(G/C)(G/T)(A/G)(A/G)TT(G/T)GC(G/A/T)GGGTGGTA \\
No. 8 & TATAACCCTTCGCCAACAGTC \\
No. 9 & GCTGCTGGGCCATCAC \\
Oligo_(dT)- & GCGAGCACAGAATTAATACGACTCACTATAGGT $12-$ \\
anchor & 18(G/A/C)N \\
Anchor & GCGAGCACAGAATTAATACGACT \\
no. 1 & \\
Anchor & CGCGGATCCGAATTAATACGACTCACTATAGG \\
no. 2 & \\
SOD no. 1 & CAAGGTCACCGGCTCCATCG \\
SOD no. 2 & CAAGCGGGACGGGGACCAG \\
\hline
\end{tabular}

For the 3' RACE experiment, cDNA was synthesized using an oligo_(dT)-anchor primer and Expand reverse transcriptase (Roche) and then used as template in a PCR reaction using gene-specific (primer no. 1) and anchor (anchor no. 1) primers. A second PCR was performed using nested gene-specific (primer no. 2) and anchor (anchor no. 2) primers. A 2-kb PCR product that subsequently was found to have arisen from annealing of the oligo_(dT)-anchor primer to a run of 21 adenosine residues immediately downstream of the GcSTUA stop codon (TAA) was cloned into pGEMT-Easy and sequenced. In the 5' RACE experiment, terminal transferase was used to add a homopolymeric A-tail to the $3^{\prime}$ end of cDNA synthesized using a gene-specific primer (primer no. 6). The cDNA then was amplified by PCR using a nested gene-specific primer (primer no. 4) and the oligo(dT)-anchor primer. The main PCR product was cloned into pGEMT-Easy and sequenced. The sequence data suggested that this product probably arose from annealing of the oligo(dT)-anchor primer to a run of 10 internal adenosine residues (complementary to residues 2,360 to 2,369 of the 7.4-kb XhoI/EcoRV insert in plasmid pXHE) rather than a terminal transferase-added tail.

Construction the GcSTUA deletion and restoration vectors.

The gene-deletion vector $(\mathrm{pSXH})$ was constructed in three steps. First, a 2.0-kb SmaI fragment from the GcSTUA promoter region was subcloned into the SmaI site of pBlueScriptII and a plasmid (pSMA20), with the insert in the required orientation identified by restriction enzyme mapping. Then, a 2.6-kb XhoI fragment containing $772 \mathrm{bp}$ from the $3^{\prime}$ end of the GcSTUA ORF was inserted into the XhoI site of pSMA20 and a plasmid (pSX) with the insert in the required orientation identified by restriction enzyme mapping. Finally, a 3.2-kb HindIII fragment that contained a hygromycin resistance cassette was transferred from the plasmid pFAT3 (Fitzgerald et al. 2003) into the HindIII site of plasmid pSX. The orientation of the insert in the deletion vector was established by restriction enzyme mapping and the plasmid was linearized with ApaI before being used to transform G. cingulata.

The complementation vector was constructed by cloning the 5.3-kb SalI fragment containing GcSTUA and flanking sequences from plasmid pXHE into plasmid pBC-phleo (Silar 1995). The 5.3-kb SalI fragment first was end filled with Klenow, A tailed with Taq polymerase, and cloned into pGEMT-Easy. This insert then was excised using EcoRI and cloned into the EcoRI site in pBC-phleo. A clone containing GcSTUA in the same orientation as the phleomycin resistance gene was identified by restriction enzyme mapping and used in subsequent experiments.

The restoration vector was designed to replace the hygromycin resistance cassette in the deletion mutant D43 with the GcSTUA gene. The 3.26-kb DraI/EcoRV fragment containing the Streptoalloteichus hindustanus gene encoding a phleomycin binding protein, under the control of the A. nidulans glyceraldehyde-3-phosphate dehydrogenase promoter, was excised from the plasmid pBC-phleo (Silar 1995) and cloned into the StuI site of the 7,432-bp insert in plasmid pXHE (Fig. 2A). This placed the phleomycin resistance cassette 902 bp downstream of the GcSTUA gene. The orientation of the insert was established by restriction enzyme mapping. The selected plasmid (pXHE-phleo-R) was linearized with EcoRI before being used to transform G. cingulata.

\section{Protoplast preparation, transformation, and selection of transformants.}

Protoplasts were prepared from $G$. cingulata conidia as described by Rikkerink and associates (1994), except that the lysing enzyme was Glucanex 200G (Novozymes Switzerland, 
Dittingen) at $50 \mathrm{mg} \mathrm{ml}^{-1}$ and the incubation was performed at $25^{\circ} \mathrm{C}$ for 16 to $20 \mathrm{~h}$. Transformation of protoplasts was performed as described by Vollmer and Yanofsky (1986), except that neither spermidine nor heparin was added to the DNA. Aliquots $(100 \mu \mathrm{l})$ of the transformation mixture were mixed with 5 $\mathrm{ml}$ of regeneration medium $(2.4 \% \mathrm{wt} / \mathrm{vol}$ potato dextrose broth, $\mathrm{pH} 6.5$, containing $27 \% \mathrm{wt} / \mathrm{vol}$ sucrose) containing $0.8 \%$ agar and poured onto regeneration medium containing $1.5 \%$ agar. After incubation at $25^{\circ} \mathrm{C}$ overnight, the plates were overlaid with $15 \mathrm{ml}$ of potato dextrose agar containing the appropriate antibiotic (hygromycin B at $200 \mu \mathrm{g} \mathrm{ml}^{-1}$ or phleomycin at $8 \mu \mathrm{g} \mathrm{ml}^{-1}$ ). The plates were incubated at $25^{\circ} \mathrm{C}$ for a further 3 to 5 days and colonies that emerged on the agar surface transferred to fresh selective potato dextrose agar plates. Single conidia were isolated prior to subsequent analysis of the transformants.

\section{Southern analysis.}

DNA was isolated and Southern blot analysis performed as described by Plummer and associates (2004).

\section{Adhesion assay for conidia.}

Conidia $\left(10^{4}\right)$, from cultures grown on potato dextrose agar plates for 7 days were washed with water and then incubated at $25^{\circ} \mathrm{C}$ on the surface of polystyrene petri dishes for $2 \mathrm{~h}$. The conidia in marked but randomly selected regions were counted. Each marked area contained at least 100 conidia. Following addition of water $(25 \mathrm{ml})$, the petri dish was shaken at $50 \mathrm{rpm}$ on a reciprocal shaker for $5 \mathrm{~min}$. The water wash then was removed and conidia remaining in the marked areas were counted.

\section{Appressorial penetration assay.}

Appressorial penetration of onion epidermal cells was assayed at $22^{\circ} \mathrm{C}$ as described for $M$. grisea (Xu et al. 1997). The adaxial surface of the peel was inoculated with approximately 5,000 conidia. Images collected using a MagnaFire S99802 camera (Olympus, Tokyo) at sequential focal planes through the peel were examined to establish whether penetration had occurred.

\section{Induction of appressoria \\ and the incipient cytorrhysis assay.}

Induction of appressorium formation on a hydrophobic surface was performed using polystyrene petri dishes inoculated with conidia as described for the adhesion assay. Appressorium formation on apple wax-coated glass slides was performed as described by Plummer and associates (2004). In both assays, appressoria were counted after $16 \mathrm{~h}$ of incubation at $22^{\circ} \mathrm{C}$. Induction of appressorium formation on onion epidermal peels was assessed after $24 \mathrm{~h}$ of incubation of onion epidermal peels at $22^{\circ} \mathrm{C}$ inoculated with conidia as described for the penetration assay.

For the incipient cytorrhysis assay (Howard et al. 1991), appressoria were induced on polystyrene petri dishes as described above except that, after either 12 or $24 \mathrm{~h}$, the water was replaced by a glycerol solution and the percentage of collapsed appressoria was determined.

\section{Visualization of glycogen and lipid during appressorium development.}

Appressorium formation was induced on the hydrophobic surface of polystyrene petri dishes. Intracellular lipid droplets were visualized using the fluorescent dye Nile Red (Greenspan et al. 1985). Glycogen was visible as yellowish-brown deposits after staining with iodine (Weber et al. 1998).

\section{Pathogenicity assays.}

Pathogenicity was assayed, at $25^{\circ} \mathrm{C}$, on unwounded Granny Smith apple fruit using the method described by Brook (1977), except that the fruit were surface sterilized, as described by Plummer and associates (2004), before being placed in contact with $0.5 \mathrm{ml}$ of inoculum $\left(0.5 \times 10^{5}\right.$ conidia $)$. The apple fruit were left in contact with the conidia for $72 \mathrm{~h}$ and then incubated, without drying, in the light for a further 9 days.

Pathogenicity on wounded Granny Smith apple fruit was assayed as described by Plummer and associates (2004), using a $50-\mu l$ droplet of inoculum $\left(0.5 \times 10^{5}\right.$ conidia $)$, except that puncture wounds were made prior to inoculation with conidia. The diameter and firmness of the lesions was measured 14 days after inoculation. Firmness was determined using an Effegi penetrometer (model FT 011; Facchini, Alfonsine, Italy) fitted with a $10-\mathrm{mm}$ probe and mounted on a drill-press stand, at a point halfway between the puncture site and the edge of the lesion. The apple surface also was examined using a Leica MZ12 dissecting microscope. Sterile water was used as the negative control in both assays.

\section{Statistical analysis.}

Student's $t$ test was performed using the online calculator provided by GraphPad Software (San Diego, CA, U.S.A.) and Fisher's exact test was performed using the online software maintained by the Physics Department of the College of Saint Benedict and Saint John's University (St. Joseph, MN, U.S.A.).

\section{ACKNOWLEDGMENTS}

This work was supported by a grant from the Marsden Fund, Royal Society of New Zealand (contract MAU001). We thank P. R. Johnston, C. H. Cheng, S. G. Zhang, and M. D. Templeton for helpful discussions; and R. E. Bradshaw for the plasmid pBC-phleo.

\section{LITERATURE CITED}

American Phytopathological Society Public Policy Board. 2006. Microbial Genomic Sequencing. Perspectives of the American Phytopathological Society. American Phytopathological Society, St. Paul, MN, U.S.A. Published online.

Aramayo, R., Peleg, Y., Addison, R., and Metzenberg, R. 1996. Asm- $1^{+}$, a Neurospora crassa gene related to transcriptional regulators of fungal development. Genetics 144:991-1003.

Bockmuhl, D. P., and Ernst, J. F. 2001. A potential phosphorylation site for an A-type kinase in the Efg1 regulator protein contributes to hyphal morphogenesis of Candida albicans. Genetics 157:1523-1530.

Borneman, A. R., Hynes, M. J., and Andrianopoulos, A. 2002. A basic helix-loop-helix protein with similarity to the fungal morphological regulators, Phd1p, Efg1p and StuA, controls conidiation but not dimorphic growth in Penicillium marneffei. Mol. Microbiol. 44:621-631.

Bowen, J. K., Templeton, M. D., Sharrock, K. R., Crowhurst, R. N., and Rikkerink, E. H. A. 1995. Gene inactivation in the plant pathogen Glomerella cingulata: Three strategies for the disruption of the pectin lyase gene pnlA. Mol. Gen. Genet. 246:196-205.

Brook, P. J. 1977. Glomerella cingulata and bitter rot of apple. N. Z. J. Agric. Res. 20:547-555.

Choi, W., and Dean, R. A. 1997. The adenylate cyclase gene MAC1 of Magnaporthe grisea controls appressorium formation and other aspects of growth and development. Plant Cell 9:1973-1983.

Clark, S. J., Templeton, M. D., and Sullivan, P. A. 1997. A secreted aspartic proteinase from Glomerella cingulata: Purification of the enzyme and molecular cloning of the cDNA. Microbiology 143:13951403 .

Clutterbuck, A. J. 1969. A mutational analysis of conidial development in Aspergillus nidulans. Genetics 63:317-27.

Doedt, T., Krishnamurthy, S., Bockmuhl, D. P., Tebarth, B., Stempel, C., Russell, C. L., Brown, A. J., and Ernst, J. F. 2004. APSES proteins regulate morphogenesis and metabolism in Candida albicans. Mol. Biol. Cell 15:3167-3180.

D'Souza, C. A., and Heitman, J. 2001. Conserved cAMP signaling cascades regulate fungal development and virulence. FEMS (Fed. Eur. Microbiol. Soc.) Microbiol. Rev. 25:349-364.

Dutton, J. R., Johns, S., and Miller, B. L. 1997. StuAp is a sequence-specific transcription factor that regulates developmental complexity in Aspergillus nidulans. EMBO (Eur. Mol. Biol. Organ.) J. 16:5710-5721. 
Ebenebe, A. C. 1980. Onion twister disease caused by Glomerella cingulata in northern Nigeria. Plant Dis. 64:1030-1032.

Fitzgerald, A. M., Mudge, A. M., Gleave, A. P., and Plummer, K. M. 2003. Agrobacterium and PEG-mediated transformation of the phytopathogen Venturia inaequalis. Mycol. Res. 107:803-810.

Galvan, G. A., Wietsma, W. A., Putrasemedja, S., Permadi, A. H., and Kik, C. 1997. Screening for resistance to anthracnose (Colletotrichum gloeosporioides Penz.) in Allium cepa and its wild relatives. Euphytica 95:173-178.

Gimeno, C. J., and Fink, G. R. 1994. Induction of pseudohyphal growth by overexpression of PHD1, a Saccharomyces cerevisiae gene related to transcriptional regulators of fungal development. Mol. Cell. Biol. $14: 2100-2112$.

Greenspan, P., Mayer, E. P. and Fowler, S. D. 1985. Nile red: A selective fluorescent stain for intracellular lipid droplets. J. Cell Biol. 100:965-973.

Gurr, S. J., Unkles, S. E., and Kinghorn, J. R. 1987. The structure and organization of nuclear genes of filamentous fungi. Pages 93-139 in: Gene Structure in Eukaryotic Microbes. J. R. Kinghorn, ed. IRL Press, Oxford.

Howard, R. J., Ferrari, M. A., Roach, D. H., and Money, N. P. 1991. Penetration of hard substrates by a fungus employing enormous turgor pressures. Proc. Natl. Acad. Sci. U.S.A. 88:11281-11284.

Kershaw, M. J., and Talbot, N. J. 1998. Hydrophobins and repellents: Proteins with fundamental roles in fungal morphogenesis. Fungal Genet. Biol. 23:18-33

Kim, Y. K., Kawano, T., Li, D., and Kolattukudy, P. E. 2000. A mitogenactivated protein kinase kinase required for induction of cytokinesis and appressorium formation by host signals in the conidia of Colletotrichum gloeosporioides. Plant Cell 12:1331-1343.

Korting, H. C., Hube, B., Oberbauer, S., Januschke, E., Hamm, G., Albrecht, A., Borelli, C., and Schaller, M. 2003. Reduced expression of the hyphal-independent Candida albicans proteinase genes SAP1 and SAP3 in the efg1 mutant is associated with attenuated virulence during infection of oral epithelium. J. Med. Microbiol. 52:623-632.

Lo, H. J., Kohler, J. R., DiDomenico, B., Loebenberg, D., Cacciapuoti, A. and Fink, G. R. 1997. Nonfilamentous C. albicans mutants are avirulent. Cell 90:939-949.

Mendgen, K., Hahn, M., and Deising, H. 1996. Morphogenesis and mechanisms of penetration by plant pathogenic fungi. Annu. Rev. Phytopathol. 34:367-386

Miller, K. Y., Toennis, T. M., Adams, T. H., and Miller, B. L. 1991. Isolation and transcriptional characterization of a morphological modifier: The Aspergillus nidulans stunted (stuA) gene. Mol. Gen. Genet. 227:285-292.

Miller, K. Y., Wu, J., and Miller, B. L. 1992. StuA is required for cell pattern formation in Aspergillus. Genes Dev. 6:1770-1782.

Mitchell, T. K., Thon, M. R., Jeong, J.-S., Brown, D., Deng, J., and Dean, R. A. 2003. The rice blast pathosystem as a case study for the development of new tools and raw materials for genome analysis of fungal plant pathogens. New Phytol. 159:53-61.

Ohara, T., and Tsuge, T. 2004. FoSTUA, encoding a basic helix-loop-helix protein, differentially regulates development of three kinds of asexual spores, macroconidia, microconidia, and chlamydospores, in the fungal plant pathogen Fusarium oxysporum. Eukaryot. Cell 3:1412-1422.

Olivain, C., and Alabouvette, C. 1999. Process of tomato root colonization by a pathogenic strain of Fusarium oxysporum f. sp. lycopersici in comparison with a non-pathogenic strain. New Phytol. 141:497-510.

Ortiz, R. 2003. Plant breeding successes in African rural development Item no. 3 in: Plant Breeding News (Edition 137). An electronic newsletter of Applied Plant Breeding sponsored by the Food and Agriculture Organization and Cornell University. C. H. Hershey, ed. The United Nations Crop and Grasslands Service of the Food and Agriculture Organization. Published online.

Park, G., Bruno, K. S., Staiger, C. J., Talbot, N. J., and Xu, J. R. 2004 Independent genetic mechanisms mediate turgor generation and penetration peg formation during plant infection in the rice blast fungus. Mol. Microbiol. 53:1695-1707.

Park, G., Xue, C., Zhao, X., Kim, Y., Orbach, M., and Xu, J. R. 2006. Multiple upstream signals converge on the adaptor protein Mst50 in Magnaporthe grisea. Plant Cell 18:2822-2835.

Pedrosa, R. A., Maffia, L. A., Mizubuti E. S. G., and Brommonschenkel, S. H. 2004. Components of onion resistance to Colletotrichum gloeosporioides. Fitopatol. Bras. 29:606-613.

Perfect, S. E., Hughes, H. B., O’Connell, R. J., and Green, J. R. 1999. Colletotrichum: A model genus for studies on pathology and fungal-plant interactions. Fungal Genet. Biol. 27:186-198.

Plummer, K. M., Clark, S. J., Ellis, L. M., Loganathan, A., Al-Samarrai, T. H., Rikkerink, E. H. A., Sullivan, P. A., Templeton, M. D., and Farley, P. C. 2004. Analysis of a secreted aspartic peptidase disruption mutant of Glomerella cingulata. Eur. J. Plant Pathol. 110:265-274.

Punt, P. J., Oliver, R. P., Dingemanse, M. A., Pouwels, P. H., and van den
Hondel, C. A. M. J. J. 1987. Transformation of Aspergillus based on the hygromycin B resistance marker from Escherichia coli. Gene 56:117-124.

Rikkerink, E. H., Solon, S. L., Crowhurst, R. N., and Templeton, M. D. 1994. Integration of vectors by homologous recombination in the plant pathogen Glomerella cingulata. Curr. Genet. 25:202-208.

Roncal, T., and Ugalde, U. 2003. Conidiation induction in Penicillium. Res. Microbiol. 154:539-546.

Shenhar, G., and Kassir, Y. 2001. A positive regulator of mitosis, Sok2, functions as a negative regulator of meiosis in Saccharomyces cerevisiae. Mol. Cell. Biol. 21:1603-1612.

Sheppard, D. C., Doedt, T., Chiang, L. Y., Kim, H. S., Chen, D., Nierman, W. C., and Filler, S. G. 2005. The Aspergillus fumigatus StuA protein governs the up-regulation of a discrete transcriptional program during the acquisition of developmental competence. Mol. Biol. Cell 16:5866-5879.

Shyamala, V., and Ames, G. F. 1989. Genome walking by single-specificprimer polymerase chain reaction: SSP-PCR. Gene 84:1-8.

Silar, P. 1995. Two new easy to use vectors for transformations. Fungal Genet. Newslett. 42:73.

Sohn, K., Urban, C., Brunner, H., and Rupp, S. 2003. EFG1 is a major regulator of cell wall dynamics in Candida albicans as revealed by DNA microarrays. Mol. Microbiol. 47:89-102.

Sonneborn, A., Bockmuhl, D. P., and Ernst, J. F. 1999. Chlamydospore formation in Candida albicans requires the Efg1p morphogenetic regulator. Infect. Immun. 67:5514-5517.

Srikantha, T., Tsai, L. K., Daniels, K., and Soll, D. R. 2000. EFG1 null mutants of Candida albicans switch but cannot express the complete phenotype of white-phase budding cells. J. Bacteriol. 182:1580-1591.

Stoldt, V. R., Sonneborn, A., Leuker, C. E., and Ernst, J. F. 1997. Efg1p, an essential regulator of morphogenesis of the human pathogen Candida albicans, is a member of a conserved class of bHLH proteins regulating morphogenetic processes in fungi. EMBO (Eur. Mol. Biol. Organ.) J. 16:1982-1991.

Teertstra, W. R., Deelstra, H. J., Vranes, M., Bohlmann, R., Kahmann, R. Kamper, J., and Wosten, H. A. 2006. Repellents have functionally replaced hydrophobins in mediating attachment to a hydrophobic surface and in formation of hydrophobic aerial hyphae in Ustilago maydis. Microbiology 152:3607-3612.

Templeton, M. D., Sharrock, K. R., Bowen, J. K., Crowhurst, R. N., and Rikkerink, E. H. 1994. The pectin lyase-encoding gene ( $p n l)$ family from Glomerella cingulata: Characterization of pnlA and its expression in yeast. Gene 142:141-146.

Thines, E., Weber, R. W., and Talbot, N. J. 2000. MAP kinase and protein kinase A-dependent mobilization of triacylglycerol and glycogen during appressorium turgor generation by Magnaporthe grisea. Plant Cell 12:1703-1718.

Tsuji, G., Fujii, S., Tsuge, S., Shiraishi, T., and Kubo, Y. 2003. The Colletotrichum lagenarium Ste12-like gene CST1 is essential for appressorium penetration. Mol. Plant-Microbe Interact. 16:315-325.

Tucker, S. L., and Talbot, N. J. 2001. Surface attachment and pre-penetration stage development by plant pathogenic fungi. Annu. Rev. Phytopathol. 39:385-417

Vollmer, S. J., and Yanofsky, C. 1986. Efficient cloning of genes of Neurospora crassa. Proc. Natl. Acad. Sci. U.S.A. 83:4869-4873.

Wang, Z. Y., Jenkinson, J. M., Holcombe, L. J., Soanes, D. M., VeneaultFourrey, C., Bhambra, G. K., and Talbot, N. J. 2005. The molecular biology of appressorium turgor generation by the rice blast fungus Magnaporthe grisea. Biochem. Soc. Trans. 33:384-388.

Ward, M. P., Gimeno, C. J., Fink, G. R., and Garrett, S. 1995. SOK2 may regulate cyclic AMP-dependent protein kinase-stimulated growth and pseudohyphal development by repressing transcription. Mol. Cell. Biol. 15:6854-6863.

Weber, R. W. S., Pitt, D., and Webster, J. 1998. Teaching techniques for mycology: 3. Amylase secretion by Aspergillus oryzae. Mycologist 12:8-9.

Wu, J., and Miller, B. L. 1997. Aspergillus asexual reproduction and sexual reproduction are differentially affected by transcriptional and translational mechanisms regulating stunted gene expression. Mol. Cell. Biol. 17:6191-201.

Xu, J. R., and Hamer, J. E. 1996. MAP kinase and cAMP signaling regulate infection structure formation and pathogenic growth in the rice blast fungus Magnaporthe grisea. Genes Dev. 10:2696-2706.

$\mathrm{Xu}, \mathrm{J}-\mathrm{R}$., Urban, M., Sweigard, J. A., and Hamer, J. E. 1997. The CPKA gene of Magnaporthe grisea is essential for appressorial penetration. Mol. Plant-Microbe Interact. 10:187-194.

Yamauchi, J., Takayanagi, N., Komeda, K., Takano, Y., and Okuno, T. 2004. cAMP-pKA signaling regulates multiple steps of fungal infection cooperatively with Cmk1 MAP kinase in Colletotrichum lagenarium. Mol. Plant-Microbe Interact. 17:1355-1365

Yang, Z., and Dickman, M. B. 1999. Colletotrichum trifolii mutants disrupted in the catalytic subunit of cAMP-dependent protein kinase are nonpathogenic. Mol. Plant-Microbe Interact. 12:430-439. 